\title{
Recurrent Childhood Malignant Liver Neoplasm
}

National Cancer Institute

\section{Source}

National Cancer Institute. Recurrent Childhood Malignant Liver Neoplasm. NCI

Thesaurus. Code C7839.

A hepatocellular carcinoma or hepatoblastoma that occurs during childhood and has recurred after a period of remission. 